\title{
Dermatofibrosarcoma protuberans: A review
}

\author{
Patrick J Davison BSc(Hons) MD ${ }^{1}$, Carolyn G Rowlands BSc MB BS FRCPC ${ }^{2}$, Robert C Cartotto MD FRCSC ${ }^{1}$ \\ Division of Plastic Surgery, Department of Surgery ${ }^{I}$ and Department of Pathology ${ }^{2}$, Queen's University, \\ Kingston, Ontario
}

\section{PJ Davison, CG Rowlands, RC Cartotto. Dermatofibrosarcoma protuberans: A review. Can J Plast Surg 1998;6(3):131-136.}

Dermatofibrosarcoma protuberans (DFSP) is a rare soft tissue tumour of the dermis. Diagnosis may be very difficult from both a clinical and histopathological standpoint. DFSP has a peak incidence in patients between age 10 and 50 years old, occurs with relatively equal frequency in males and females and has a predilection to occur on the trunk or proximal limbs. The tumour has a very low metastatic potential but can be very locally aggressive, requiring wide surgical resection. The possible variants of DFSP may obscure diagnosis especially in the case of fibrohistiocytic lesions such as dermatofibroma, fibromatosis and malignant fibrous histiocytoma. Immunohistological testing, while not completely specific, shows promise in improving diagnostic accuracy. Wide local excision continues to be the mainstay of treatment, although Mohs' micrographic surgery may ultimately provide superior cure rates.

Key Words: Case report, Dermatofibrosarcoma protuberans, Fibrohistiocytic tumours, Literature review

\section{Dermatofibrosarcome protuberans : revue de synthèse}

RÉSUMÉ : Le dermatofibrosarcome protuberans (DSFP) est une rare tumeur des tissus mous du derme. Le diagnostic peut être très difficile, tant d'un point de vue clinique qu'histopathologique. L'incidence de pointe du DSFP se situe entre la deuxième et la cinquième décennies de vie (soit à partir de l'âge de 10 ans [début de la deuxième décennie] jusqu'à l'âge de cinquante ans [fin de la cinquième décennie]) et la maladie affecte à peu près également les hommes et les femmes, surtout au niveau du tronc et des membres proximaux. La tumeur a un très faible potentiel métastatique, mais peut être très agressive localement, exigeant une résection chirurgicale large. Certaines variantes possibles du DSFP nuisent parfois au diagnostic, surtout dans les lésions fibrohistiocytaires, comme le dermatofibrome, la fibromatose et les histiocytomes fibreux malins. Les épreuves immuno-histologiques, bien qu'elles ne soient pas entièrement spécifiques, sembleraient prometteuses pour un diagnostic plus précis. L'incision locale large continue d'être au cœur du traitement, bien que la chirurgie micrographique de Moh puisse ultimement donner des taux de guérison supérieurs.

$\mathrm{D}$ ermatofibrosarcoma protuberans (DFSP) is a relatively uncommon soft tissue tumour that is locally aggressive but rarely metastatic. The first published case report of the tumour was by Taylor (1) in 1890. However, the tumour was not characterized as a clinicopathological entity until 1924 (2). The current name, dermatofibrosarcoma protuberans or "lump-producing fibrosarcoma of the skin", is accredited to Hoffman (3), who published three cases from his practice in 1925. Clinically and histopathologically the tumour may be very difficult to differentiate from other fibrohistiocytic tumours such as dermatofibroma, fibromatosis and malig-

Correspondence and reprints: Dr R Cartotto, Brock 3 Hotel Dieu Hospital, 166 Brock Street, Kingston, Ontario K7L 5G2. Telephone 613-544-3400 ext 2300, fax 613-544-9897 nant fibrous histiocytoma. Other lesions commonly included in the differential diagnosis include keloid, localized scleroderma and fascitis (4,5). DFSP develops slowly and may infiltrate widely, giving rise to high recurrence rates. This paper comprises a case report, followed by a detailed review of the clinicopathological features of DFSP and its management.

\section{CASE PRESENTATION}

A 73-year-old man was referred with a four-year history of a progressively enlarging nodule on the posterior aspect of the right shoulder (Figure 1). Examination revealed a $20 \mathrm{~mm}$ red plaque with a firm and adherent subcutaneous circumferential extension for $2 \mathrm{~cm}$ in all directions. Initial biopsy did not identify a cellular dermatofibroma or a DFSP. Because the 


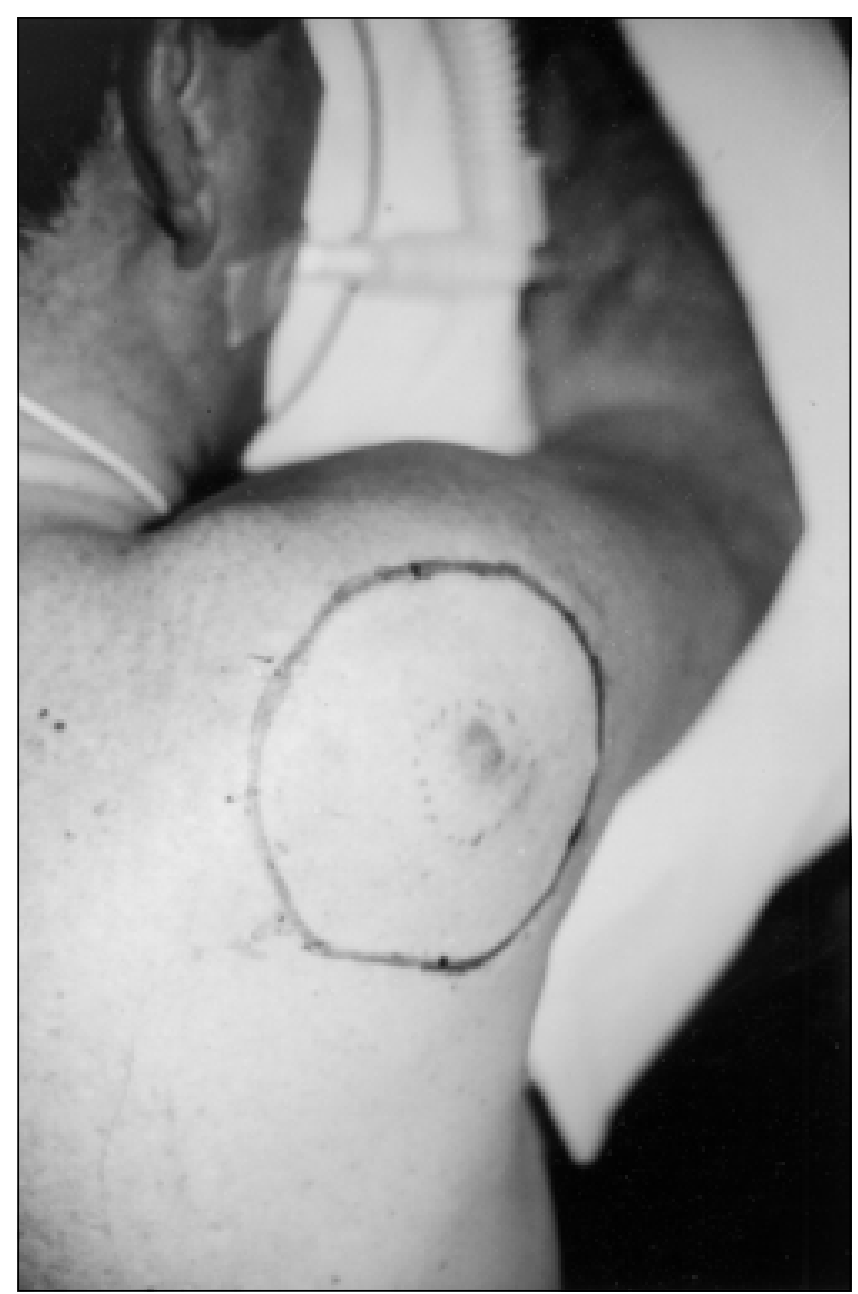

Figure 1) Planned wide local excision of dermatofibrosarcoma protuberans from right shoulder. Dotted line indicates palpable subcutaneous extension of tumour

lesion was clinically most consistent with DFSP, the patient underwent a wide excision, with a $3 \mathrm{~cm}$ margin of normal tissue around the grossly visible and palpable limits of the tumour (Figure 1). Intraoperative frozen section confirmed that the deep margin, including the deep investing fascia, was clear. The defect was reconstructed with a split thickness skin graft.

Histological examination of the tumour revealed a vague storiform arrangement of slender spindle cells, rare mitotic figures and immunoreactivity with CD 34 antibody, features consistent with DFSP (Figures 2-4). Two years after treatment, the patient remains free from local recurrence.

\section{DISCUSSION}

\section{Clinical features}

Clinically the tumour usually presents as a solitary raised cutaneous nodule with a red to blue hue (4). Growth of the neoplasm is most often painless and may progress from a dermal plaque to form adjacent nodules that can eventually coalesce into a single structure (6). DFSP lesions usually remain mobile on the underlying fascia but often are very adherent to the overlying epidermis (7). Expansion of DFSP can proceed at various rates ranging from three weeks (6) to several decades (7). Later stages of tumour progression may feature skin atrophy that can result in local trauma, infection and ulceration of the lesion (6). Patients often do not seek medical attention until such local changes develop.

DFSP is most often found on the trunk or proximal limbs, although it may occur at any anatomical location $(8,9)$. The tumours are aggressive locally; their reported size ranges from a few millimetres to well over $20 \mathrm{~cm}$ in diameter $(4,6,7)$. The larger tumours are usually seen when medical attention has not been sought or in cases of repeated recurrence.

The incidence of DFSP is relatively uncommon compared with that of other soft tissue tumours. Over 1200 cases of DFSP have been reported in the literature (5), comprising slightly less than $0.1 \%$ of all soft tissue tumours $(6,7,10)$. In a series reported by Bendix-Hansen et al (11), DFSP represented $7 \%$ of all soft tissue sarcomas and had an annual incidence of $0.08 / 100,000$. DFSP occurs in all age groups, ranging from the neonate (12-14) to the elderly, with a peak incidence between ages 10 and 50 years $(9,15,16)$. DFSP is slightly more common in males $(11,16)$.

\section{Pathology}

On gross examination, DFSP is usually a single, sometimes multinodular, greyish-white tumour. While the tumour may appear to be circumscribed, microprojections of the tumour can be far-reaching, contributing to the high local recurrence rate of DFSP (15). Some lesions may display a foci of myxoid change where areas of the tumour appear translucent or gelatinous (5).

Histologically the tumour is a dermal-based proliferation of plump, relatively monomorphic spindle cells showing the classical 'storiform' or 'cartwheel' pattern with varying vascularity and collagenization (17). The storiform pattern is not unique to DFSP because dermatofibroma, malignant fibrohistiocytoma and atypical fibroxanthoma may all display a similar cellular arrangement (18). Cellularity is greatest at the centre of the lesion and gradually diminishes at the periphery where the cells become slender, gradually blending into normal tissue (9). One of the characteristic, almost diagnostic features is the lace-like or 'honeycomb' infiltration of subcutaneous fat. Irregular projections of tumour tissue extend laterally and superficially, often causing atrophy and enveloping sweat glands and pilosebaceous units (7). Later stages of DFSP infiltration may become aggressive, with the tumour extending into fascia and muscle planes (17).

Mitotic figures are relatively rare, even in cellular areas and in rapidly growing tumours $(15,16)$. Chattopadhyay et al (10) suggested that tumours with fewer than five mitoses per 10 different high power fields have a less aggressive course. In one series, three of five lesions with metastases were shown to have eight mitoses per 10 different high power fields (6). Others have speculated that aneuploidy may predict a more aggressive tumour (19). Necrosis is rare and, if present, minimal. 


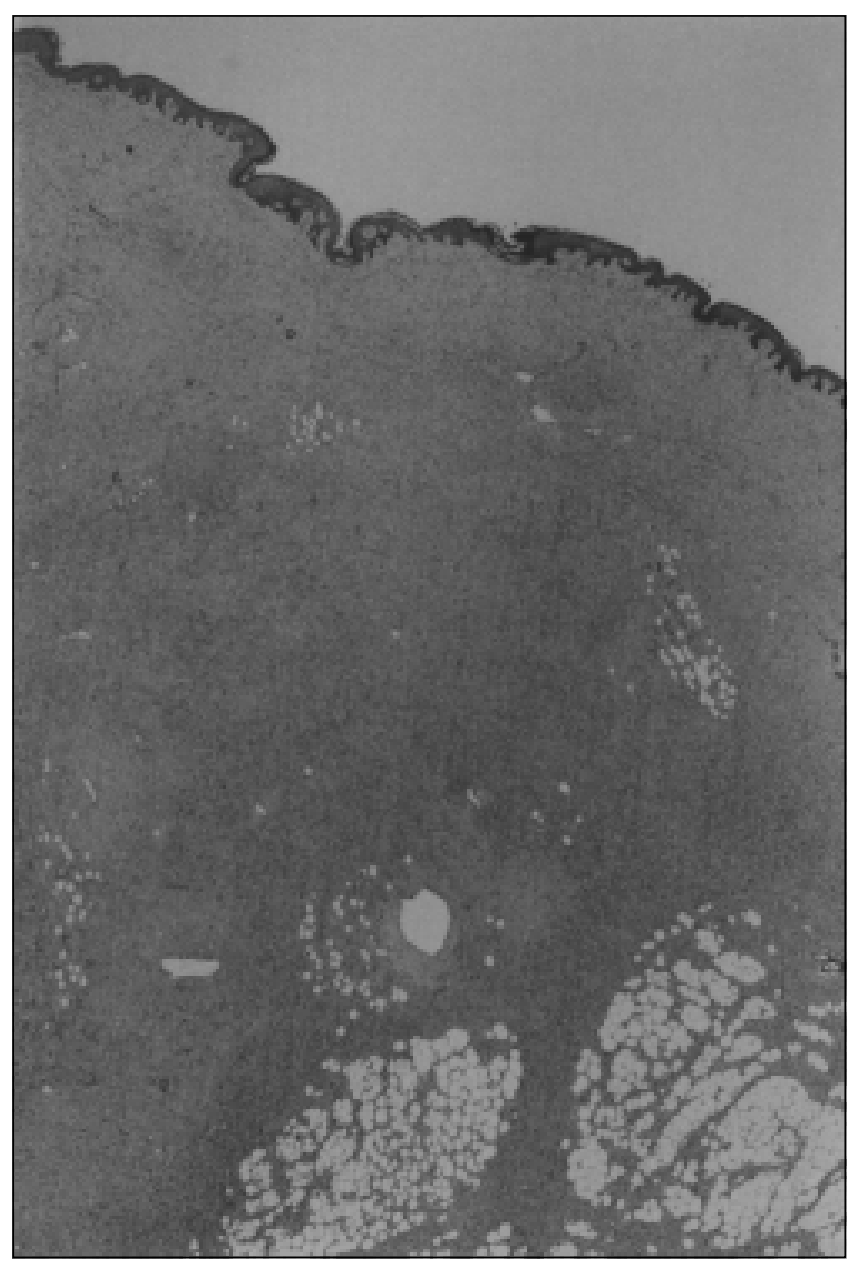

Figure 2) Dense proliferation of spindle cells occupying the entire dermis and infiltrating the subcutaneous fat with the characteristic lacelike or honeycomb pattern are presented (hematoxylin, phloxine and saffron stain, original magnification $\times 20$ )

\section{Variant DFSP lesions}

A major obstacle in diagnosis is that DFSP may exist in one of several variant forms. One of the most frequent abberations is a lesion with myxoid features. It has been estimated that up to $15 \%$ of all DFSP tumours display some degree of myxoid change $(18,20,21)$. Previously, myxoid change was thought to be predominantly a feature seen in recurrences, but recent studies have refuted this because microscopic myxoid areas are often seen in initial lesions (22-24). Myxoid foci are characterized by a decrease of storiform or cartwheel patterns, and accumulations of interstitial ground substance containing mucopolysaccharides (5). Myxoid change may interfere with both gross and microscopic determination of tumour boundaries (22).

The so-called Bednar tumour or pigmented DFSP is an unusual variation containing scattered melanin-bearing dendritic cells. Although too rare to be appreciated clinically, approximately $5 \%$ of all DFSP tumours may possess melaninsynthesising cells (25). Bednar (26) first described this pigmented lesion in 1957 as a neurofibroma variant. However S-100 protein, present in neural and melanocytic tumours, has not been reported in the pigmented variant or any other

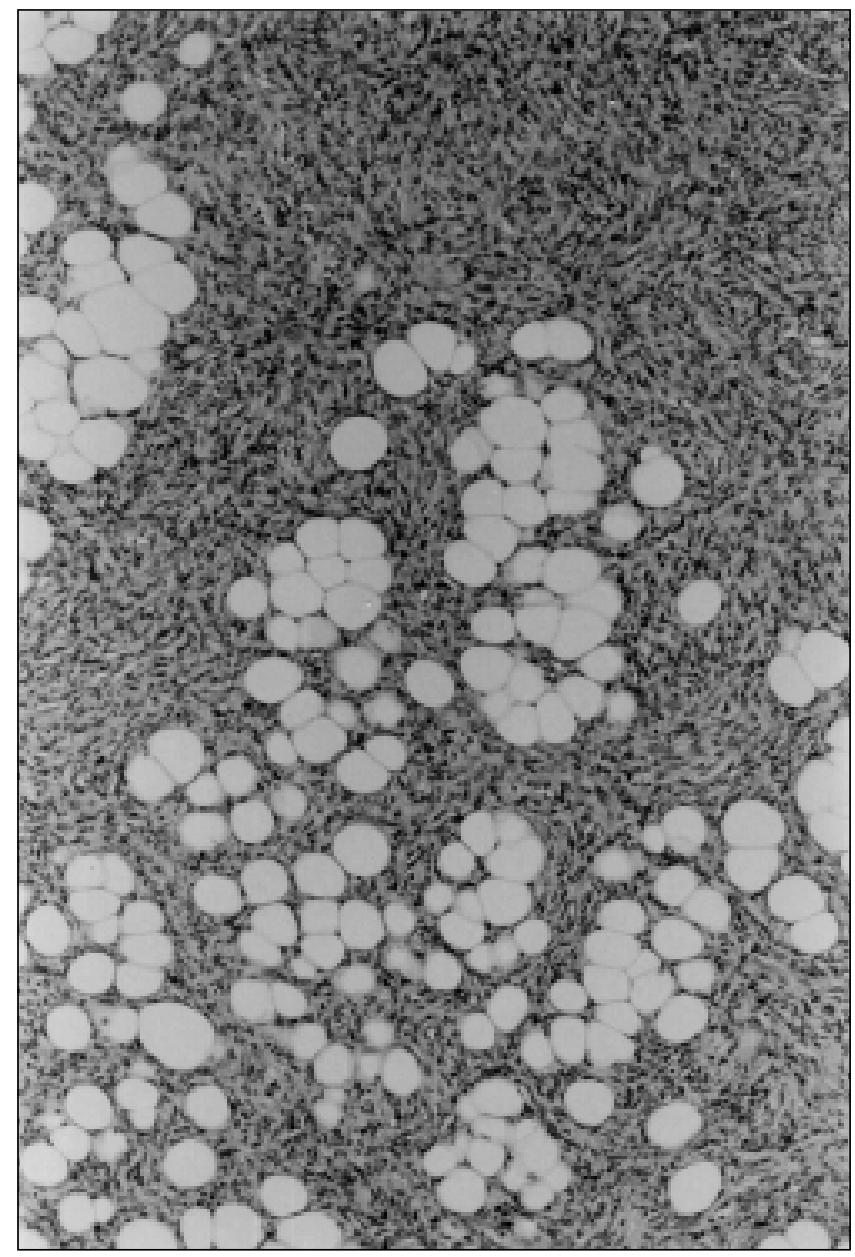

Figure 3) Relatively monomorphous plump spindle cells arranged in a storiform pattern and infiltrating subcutaneous fat are presented (same view as in Figure 2 but with greater magnification) (hematoxylin, phloxine and saffron stain, original magnification $\times 100$ )

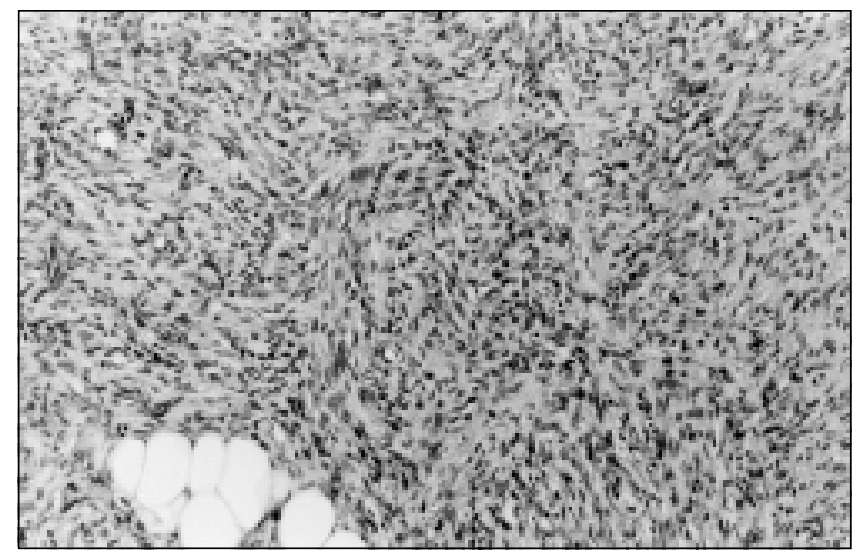

Figure 4) Cells showing little atypia in a densely collagenous stroma; mitoses are not apparent. The storiform pattern is very visible (hematoxylin, phloxine and saffron stain, original magnification $\times 200$ )

DFSP (5). These pigmented tumours range from the rare grossly darkened lesions to others where pigmentation can only be appreciated microscopically (25). Typically, it is only the grossly pigmented variety of DFSP that adds confusion to the clinical diagnosis. 
Another variant that creates a diagnostic challenge is DFSP lesions with hemorrhagic features, which may mimic vascular neoplasms. Final diagnosis may require immunohistochemical staining and electron microscopy to exclude vascular origin (27). While this variant is very rare it is important to recognize the possibility of a vascular neoplasm. Angiomatoid features of DFSP may also be confused with vascular variants of other fibrohistiocytic sarcomas $(28,29)$.

One final DFSP variant that may create a diagnostic difficulty is DFSP with dermal atrophy, which can be confused with dermatofibroma $(30,31)$. Atrophic variants of both DFSP and dermatofibroma may present with greater than $50 \%$ dermal loss superficial to their respective lesions, increasing the likelihood of misdiagnosis (30).

\section{Histogenesis}

A controversial aspect of DFSP is its origin. Since its discovery, researchers have debated the histogenesis of DFSP. Historically the tumour was assigned a broad spectrum of etiologies including parasitic infections (2), misplaced embryonic breast tissue $(7,16)$ and previous trauma $(6,7,16)$. Although histological examination does not support these theories, antecedent trauma continues to be cited as a possible precipitating factor in up to $20 \%$ of DFSP cases (5). This figure may reflect that the trauma calls attention to previously unrecognized lesions.

Historically, light microscopy and electron microscopy revealed characteristics suggestive of peri- or endoneural origins $(31,32)$. Concentric layers of tumour cells enveloping capillaries and ultrastructural features such as elaborate convoluted nuclei, extensive cytoplasmic processes and fibrous long-spacing collagen all pointed towards a neural origin (20). Further supporting these observations was Bednar (33) who felt the characteristic DFSP storiform pattern to be a specific feature of neural differentiation and who described the pigmented melanin containing DFSP (26).

Currently, few researchers subscribe to a neural origin theory; instead they view the endoneural and perineural features to be characteristic of fibroblastic genesis. Classic immunohistochemical markers for neural derivation (s100 protein, Leu 7 antigen and neuron-specific enolase) are absent in $\operatorname{DFSP}(34,35)$.

\section{Immunodiagnosis}

Immunohistochemical staining has generated considerable research into the diagnosis and origins of DFSP, with CD 34 and factor XIIIa being the most prominent markers under investigation. Positive CD 34 staining for DFSP was first described by Ramani et al (36) in 1990; subsequently great interest has been shown in this marker (37-43). The antigen CD 34 is a transmembrane glycoprotein encoded by a gene located on chromosome 1 (44). Cells that possess the membrane protein include endothelial cells, dermal dendritic cells and hematopoietic progenitor cells. Approximately $88 \%$ of DFSP tested for CD 34 are positive, with a strongly diffuse pattern (41). However CD 34 is not specific to DFSP and is present in a wide range of neoplasms, including endothelial cell tumours, epithelioid sarcomas, some smooth muscle tumours and peripheral neural sheath tumours. CD 34 is useful in distinguishing DFSP from dermatofibroma because dermatofibroma is usually CD 34 immunonegative $(41,42)$.

Factor XIIIa is an intracellular analogue of the fibrin stabilizer formed during the clotting cascade $(35,42)$. This antigen has been identified in various dendritic cells found in reactive lymph nodes (45), fibrohistiocytic tumours $(46,47)$ and some epithelial tumours (42). Factor XIIIa is not found within DFSP tumour cells $(35,42,48)$; however, the lesional cells are positive in $90 \%$ of dermatofibroma cases (42). While dermatofibroma contains factor XIIIa, it may only stain weakly positive $(49,50)$.

\section{Treatment}

The treatment of choice for DFSP is wide surgical excision. A $3 \mathrm{~cm}$ margin of normal tissue around the visible tumour was recommended as early as 1903 by Johnson (51). Margins of 2.5 to $3 \mathrm{~cm}$ are still commonly used $(5,6,7,16,52-55)$. Invasion of DFSP into surrounding tissue requires a $3 \mathrm{~cm}$ margin of grossly normal tissue, both peripherally and deep to the tumour $(5,11)$. This margin usually results in resection of the deep fascia (5) and, in certain anatomic locations such as the scalp, resection of the periosteum $(19,53,56)$. A recent study (57) recommends an even more aggressive approach in which deep resection is combined with removal of tissue $5 \mathrm{~cm}$ peripheral to the tumour.

Local recurrence is a well known phenomenon and is reported to occur in $11 \%$ to $73 \%$ of cases $(6,11,16,53)$. Recurrence is related to the locally aggressive biology of DFSP. These tumours have the ability to microscopically infiltrate adjacent dermis, fat, fascia, muscle and even bone well beyond the limit that can be appreciated on gross inspection of the tissues at surgery (6). The variability among studies of local recurrence rates is a function of imprecise definitions of 'wide' resection and different follow-up periods. Most local recurrences develop within one to three years (55), but recurrences as late as 19 years have been reported $(7,16)$. The risk of local recurrence is inversely related to the width of surgical resection $(53,54)$. Lymphatic invasion does not generally occur; hence prophylactic lymph node dissections are not routinely performed (6).

The low but potential metastatic ability of DFSP is now accepted (9). Large tumours (greater than $15 \mathrm{~cm}$ ) or a preceding history of multiple local recurrences may be associated with a higher risk of systemic metastases (6).

The wide resection of DFSP usually necessitates skin grafts or flaps for closure of the surgical wound. Mohs' micrographic surgery (MMS) has been advocated as a very useful method of treating DFSP. MMS has the capability of providing more complete surgical resection of the tumour while maximizing tissue preservation $(56,58-62)$. While the literature to date supports MMS as a highly effective treatment for DFSP, it has been used in only a relatively small number of cases compared with traditional wide local resection. Thus its true role, while very promising, is not yet clear. Adjuvant therapies such as radiation and systemic chemotherapy have no role in the treatment of DFSP. 


\section{REFERENCES}

1. Taylor RW. Sarcomatous tumours resembling in some respects keloid. J Cutan Genito-Urinal Dis 1890;8:384-7.

2. Dairier J, Ferrand M. Dermatofibromes progressifs et recidivants ou fibrosarcomes de la peau. Ann Dermatol Syphiligr (Paris) 1924;5:545-70.

3. Hoffman E. Uber das knollenteibende Fibrosarkom der haut (Dermatofibrosarkoma protuberans). Dermat Ztschr 1925;43:1-28.

4. Vasonez HC, Sengezer M, McGrath PC. Flap coverage of a large defect after excision of a massive dermatofibrosarcoma protuberans. Plast Reconstr Surg 1995;95:136-40.

5. Freedman RJ, Rigel DS, Kopf AW, Harris MN, Baker D. Cancer of the Skin, 4th edn. New York: JB Lippincott Co, 1992:265-87.

6. McPeak CJ, Cruz T, Nicastri AD. Dermatofibrosarcoma protuberans: An analysis of 86 cases - five with metastasis. Ann Surg 1967;166:803-16.

7. Pack GT, Tabah EJ. Dermatofibrosarcoma protuberans: A report of thirty-nine cases. Arch Surg 1951;63:391-411.

8. Rabinowitz LG, Luchetti ME, Segura AD, Esterly NB. Acrally occurring dermatofibrosarcoma protuberans in children and adults. J Dermatol Surg Oncol 1994;20:655-9.

9. Bock JE, Andreasson B, Thorn A, Holck S. Dermatofibrosarcoma protuberans of the vulva. Gynecol Oncol 1985;20:129-35.

10. Chattopadhyay TK, Singh MK. Dermatofibrosarcoma protuberans: A clinicopathological study of ten cases. Jpn J Surg 1986;16:435-8.

11. Bendix-Hansen K, Myhre-Jensen O, Kaae S. Dermatofibrosarcoma protuberans: A clinico-pathological study of nineteen cases and review of world literature. Scand J Plast Reconstr Surg 1983;17:247-52.

12. Schvarcz LW. Congenital dermatofibrosarcoma protuberans of the hand. Hand 1977;9:182-6.

13. Annessi G, Cimitan A, Girolomoni G, Giannetti A. Congenital dermatofibrosarcoma protuberans. Pediatr Dermatol 1993;10:40-2.

14. McKee PH, Fletcher CDM. Dermatofibrosarcoma protuberans presenting in infancy and childhood. J Cutan Pathol 1991;18:241-6.

15. Koh CK, Ko CB, Bury HPR, Wyatt EH. Dermatofibrosarcoma protuberans. Int J Dermatol 1995;34:256-60.

16. Taylor HB, Helwig EB. Dermatofibrosarcoma protuberans: A study of 115 cases. Cancer 1962;15:717-25.

17. Lever WF, Schaumburg-Lever G. Tumours of fibrous tissue. In: Lever WF, ed. Histopathology of the Skin. New York: JB Lippincott Co, 1983:597-622.

18. Clark DP. Management of uncommon malignant tumours. In: Wheeland P, ed. Cutaneous Surgery. Philadelphia: WB Saunders Company, 1994.

19. Rockley PF, Robison JK, Magid M, Goldblats E. Dermatofibrosarcoma protuberans of the scalp. A series of cases. J Am Acad Dermatol 1989;21:278-83.

20. Hashimoto K, Brownstein MH, Jakobiec FA. Dermatofibrosarcoma protuberans: A tumour with perineural and endoneural cell features. Arch Dermatol 1974;110:874-85.

21. Allen PW. Myxoid tumours of soft tissues. Pathol Ann 1980;15:133-92.

22. Frierson HF, Cooper PH. Myoid variant of dermatofibrosarcoma protuberans. Am J Surg Pathol 1983;5:445-50.

23. Fletcher CD, Evans BJ, MacArtney JC, Smith N, Wilson Jones E, McKee PH. Dermatofibrosarcoma protuberans: a clinicopathological and immunohistochemical study with a review of the literature. Histopathology 1985;9:921-38.

24. Hess KA, Hanke CW, Estes NC, et al. Chemosurgical reports: Myxoid dermatofibrosarcoma protuberans. J Dermatol Surg Oncol 1985;11:268-71.

25. Fletcher CD, Theaher JM, Flanagan A, Krausz T. Pigmented dermatofibrosarcoma protuberans (Bednar tumour): melanocytic colonization or neuroectodermal differentiation? A clinicopathological and immunohistochemical study. Histopathology 1988;13:631-43.

26. Bednar B. Storiform neurofibromas of the skin, pigmented and nonpigmented. Cancer 1957;10:368-76.

27. Costa MJ, McGlothlen L, Pierce M, Munn R, Vogt PJ. Angiomatoid features in fibrohistiocytic sarcomas: Immunohistochemical, ultrastructural, and clinical distinction from vascular neoplasms. Arch Pathol Lab Med 1995;119:1065-71.

28. Coffin CM, Dehner LP. Vascular tumours in children and adolescents: A clinicopathologic study of 228 tumours in 22 patients. Pathol Ann 1993;28:97-120.

29. Costa MJ, Weiss SW. Angiomatoid malignant fibrous histiocytoma: A follow-up study of 108 cases with evaluation of possible histologic predictors of outcome. Am J Surg Pathol 1990;14:1126-32.

30. Zelger BW, Ofner D, Zelger BG. Atrophic variants of dermatofibrosarcoma protuberans. Histopathology 1995;26:519-27.

31. Zelger B, Sidoroff A, Stanzl U, et al. Deep penetrating dermatofibroma versus dermatofibrosarcoma protuberans: A clinicopathologic comparison. Am J Surg Pathol 1994;18:677-86.

32. Alguacil-Garcia A, Unni KK, Goellner JR. Histogenesis of dermatofibrosarcoma protuberans: An ultrastructural study. Am J Clin Pathol 1978;69:427-34.

33. Bednar B. Storiform neurofibroma in the core of naevocellular naevi. J Pathol 1970;101:199-201.

34. Lautier R, Wolff HH, Jones RE. An immunohistochemical study of dermatofibrosarcoma protuberans supports its fibroblastic character and contradicts neurectodermal or histiocytic components. Am J Dermatopathol 1990;12:25-30.

35. Dominguez-Malagon HR, Ordonez NG, MacKay B. Dermatofibrosarcoma protuberans: Ultrastructural and immunocytochemical observations. Ultrastruct Pathol 1995;19:281-9.

36. Ramani P, Bradley NJ, Fletcher CD. QBEND/10, a new monoclonal antibody to endothelium: Assessment of its diagnostic utility in paraffin sections. Histopathology 1990;17:237-42.

37. Fitzgibbon JF, Henner MS, Swanson PE, Wick MR. CD 34 staining of cutaneous fibrohistiocytic tumours specificity sensitivity as a tumour marker for dermatofibrosarcoma protuberans. J Cutan Pathol 1992;19:530. (Abst)

38. Aiba S, Tabata N, Ishii H, Ootani H, Tagami H. Dermatofibrosarcoma protuberans is a unique fibrohistiocytic tumour expressing CD34. Br J Dermatol 1992;127:79-84.

39. Kamino H, Burchette J, Garcia JA. Immunostaining for CD34 in plaque and nodular areas of dermatofibrosarcoma protuberans. J Cutan Pathol 1992;19:530. (Abst)

40. Kutzner H. Expression of the human progenitor cell antigen CD34 (HPCA-1) distinguishes dermatofibrosarcoma protuberans from fibrous histiocytoma in formalin-fixed, paraffin-embedded tissue. J Am Acad Dermatol 1993;28:613-7.

41. Cohen PR, Rapini RP, Farhood AI. Dermatofibroma and dermatofibrosarcoma protuberans: Differential expression of CD34 and factor XIIIa. Am J Dermatopathol 1993;20:521-32. (Lett)

42. Abenoza P, Lillemore T. CD34 and factor XIIIa in the differential diagnosis of dermatofibroma and dermatofibrosarcoma protuberans. Am J Dermatopathol 1993;15:429-34.

43. Altman DA, Nickoloff BJ, Fivenson DP. Dermatofibrosarcoma protuberans strongly express CD34. J Cutan Pathol 1992;19:522. (Abst)

44. Greaves MF, Brown J, Molgaard HV, et al. Molecular features of CD34: A hemopoietic cell-associated molecule. Leukemia 1992;6(Suppl 1):31-6.

45. Fear JD, Jackson P, Gray C, MIloszewski KJA, Losowsky MS. Localization of factor XIIIa in human tissues using an immunoperoxidase technique. J Clin Pathol 1984;37:560-3.

46. Nemes Z, Thomazy V. Factor XIIa and the classic histiocytic markers in malignant fibrous histiocytoma: A comparative immunohistochemical study. Hum Pathol 1988;19:822-9.

47. Reid MB, Gray C, Fear JD, Bird CC. Immunohistological demonstration of factors XIIIa and XIIIs in reactive and neoplastic fibroblastic fibrohistiocytic lesions. Histopathology 1986;10:1171-8

48. Baer SC, Raymen AK, Ondoneaz NG. CD34 and factor XIIIa expression in DFSP: specificity, sensitivity, and pattern of immuno staining. United States and Canada Academy of Pathology 83rd annual 
meeting, San Francisco, California, March 12-19, 1994. Lab Invest 1994;70:44a.

49. Ariza A, Bilbao JM, Rosai J. Immunohistochemical detection of epithelial membrane antigen in normal perineurial cells and perineurioma. Am J Surg Pathol 1988;12:678-83.

50. Kindbloom LG, Jacobsen GK, Jacobse M. Immunohistochemical investigations of tumours of supposed fibroblastic-histiocytic origin. Hum Pathol 1982;13:834-40.

51. Johnson JC. Fibrosarcoma cutis. J Cutan Genito-Urinal Dis 1903;21:23.

52. Burkhardt BR, Soul EH, Winkelmann RK, Ivins JC. Dermatofibrosarcoma protuberans: Study of fifty-six cases. Am J Surg 1966;111:638-44.

53. Parker TL, Zitelli JA. Surgical margins for excision of dermatofibrosarcoma protuberans. J Am Acad Dermatol 1995;32:233-6.

54. Roses DF, Valensi Q, LaTrenta G, Harris MN. Surgical treatment of dermatofibrosarcoma protuberans. Surg Gynecol Obstet 1986;162:449-52.

55. Hajdu SI. Pathology of Soft Tissue Tumours. Philadelphia: Lea \& Febider, 1979:60-8.
56. Hanke WC, Lee MW. Treatment of rare malignancies. In: Mikhail GR, ed. Mohs' Micrographic Surgery. Philadelphia: WB Saunders, 1990:261-74.

57. Arnaud EJ, Perrault M, Revol M, Servant JM, Banzet P. Surgical treatment of dermatofibrosarcoma protuberans. Plast Reconstr Surg 1997; 100:884-95.

58. Brown MC, Swanson NA. Treatment of malignant fibrous histiocytoma and atypical fibrous xanthomas with micrographic surgery. J Dermatol Surg Oncol 1989;15:1287-92.

59. Robinson JK. Dermatofibrosarcoma protuberans resected by Mohs' surgery (chemosurgery). J Am Acad Dermatol 1985;12:1093-8.

60. Goldberg DJ, Maso M. Dermatofibrosarcoma protuberans in a 9-year-old child: Treatment by Mohs' micrographic surgery. Pediatr Dermatol 1990;7:57-9.

61. Peters CW, Hanke CW, Pasarell HA, Bennet JE. Chemosurgical reports. Dermatofibrosarcoma protuberans of the face. J Dermatol Surg Oncol 1982;8:823-6.

62. Hobbs ER, Wheeland RG, Bailin PL, Ratz JL, Yetman RJ, Zins JE. Treatment of dermatofibrosarcoma protuberans with Mohs' micrographic surgery. Ann Surg 1988;207:102-7. 